The reliability of rockets, bearing in mind the V2 firing failures, was queried; but it was stated that there is no fundamental reason why they should not be perfectly safe, and a number of aireraft applications were quoted in support. The problem of jettisoning assisted take-off or booster rockets in flight without damage to the motors or the populace below was also considered. A suggestion that rocket motors might be used for assisting gliders to extreme heights so that observations of meteorological interest could be made without the corrections necessitated by the transient conditions inherent in the sounding rocket was considered impracticable. An alternative proposal was a balloon with some rocket thrust available for directional control. Among other facts brought out was that the present maximum altitude reached by a rocket is 240 miles.

The chairman summarized the discussion by stating that rocket motors could give advantages wherever simplicity is needed, wherever high energy for short periods is demanded and wherever other power plants could not operate because of lack of air. The meeting then concluded with a short colour film of some rocket motor tests, both in flight and on the ground.

\section{RADIOISOTOPE TECHNIQUES IN INDUSTRY}

$7 \mathrm{HE}$ wide use of radioisotopes in medical research has received considerable publicity; but their field of application is by no means limited to medicine, and consultations between nuclear physicists conversant with radioisotopes, and workers in other branches of seience and engineering soon reveal numerous important problems that can be tackled successfully by the use of these substances. The international conference on radioisotopes held during July 16-20, 1951, at Oxford, under the auspices of the Atomic Energy Research Establishment, Harwell, is an outstanding example of the value of such consultations. In all, ninety-eight papers were presented, grouped under the main headings of therapy and diagnosis, biochemistry, agriculture, and industrial and allied research applications, and divided into thirty separate sessions. The complete text of the proceedings of this isotopes techniques conference, including the chairmen's addresses, the papers presented and the discussions on them, is to be published in two volumes, the first of which, Vol. 2, covering Sessions 21-30 inclusive and devoted to industrial and allied research applications, has now appeared*.

For the first two Sessions, 21 and 22, dealing with general and metallurgical applications, Dr. B. Goldschmidt, of the Commissariat à l'Energie Atomique, Paris, was in the chair, and in his opening remarks he expressed gratitude to Great Britain for the liberal policy adopted with regard to the release and distribution of radioisotopes for industrial purposes to foreign countries; in addition, he paid tribute to Dr. H. Seligman, the head of the Isotopes Division at Harwell, for initiating the conference. Of the seven papers presented in the two sessions, the two main ones were by Dr. Seligman on types of applications

* Ministry of Supply. Radioisotope Techniques : Proceedings of the Isotope Techniques Conference, Oxford, July 195t, sponsored by the Atomic Finergy Research Establishment. Vol. 2 : Industrial and Allied Research Application of radioisotopes, and by Dr. R. W. Cahn on radioisotopes applied to metallurgical research. Dr. Seligman briefly reviewed the various industrial applications, mentioning, in particular, gamma radiography, static eliminators and thickness gauges. He pointed out that tracers have not been used as extensively as they might have been, particularly in problems of process control. Dr. Cahn distinguished between what he called microscopic applications in metallurgy (such as tracer methods for the measurement of selfdiffusion in metals, and autoradiography for the determination of tracer elements in alloy sections) and macroscopic applications, in which the normal experimental or industrial procedure is followed, but where, at some stage, tracer elements are introduced.

Session 23 was devoted to gamma radiography, and Mr. W. N. Blacklock, of the Ministry of Supply Aeronautical Inspection Directorate, who presided, referred to the prominent part taken by radiography in non-destructive testing. He stated that the present relatively inexpensive and abundant supply of radioisotopes largely eliminates the need for heavy and costly X-ray equipment for the testing of heavy metal components. Five papers dealt with gamma radiography tests of iron and steel castings and inspections of metal welds. These were preceded by an interesting short paper by Mr. W. S. Eastwood on the handling of radiographic sources, in which he mentioned that, in addition to radium and radon, only three radioisotopes-cobalt-60, tantalum- 182 and iridium-192, all metals-are in current use. They are prepared by the Atomic Energy Research Establishment, Harwell, in the form of small cylinders of standard sizes. Shorter-lived isotopes are also obtainable; but these are irradiated to order at Harwell in the size required and to the necessary activity. With regard to transport of the strong sources, it has to be remembered that the limits of radiation at a package surface set by British Railways are even more stringent than those of airline companies, and thus radiographic sources are transported inland by motor-car and are sent to Continental users sometimes by sea.

Mr. B. Sehuil, who spoke about radioisotopes in radiography and measurements of wall thickness, made an interesting reference to the psychological effect that radiographic control of welds has on welders who are working far away from their workshops. With radioisotopes, control and test of pipe welds are possible in the field even under the worst conditions, and it was found in Holland that when welders were aware that a radiographic inspection was in force the percentage of bad welds fell from 80 to 20 per cent. Finally, to wind up the Session, Dr. J. S. Blair described some of the safety precautions that are necessary when radioisotopes are handled.

In Session 24, on counting techniques, $\mathrm{Lr}$. S. G. Cohen and Dr. D. Carmi described counters with thin plastic walls for the detection of X-rays, and Mr. H. Herne showed how, by the use of the commonly known, but not commonly employed, property of radioisotopes-namely, the random nature of the radioactive disintegrations themselves - the isotopes could be used in an analogue computer for stochastic problems. Mr. J. L. Putnam then discussed the very important but somewhat thorny problem of the absolute measurement of the activity of radioisotopes. He stressed the need for generally accepted standards of radioactivity and mentioned some of the intercomparison measurements and absolute measurements which are being made in 
Britain. (Some of the results of these measurements have since been published; see Nature, 170, 916; 1952.)

The study of solid reactions is probably one of the main applications for radioactive tracers in physical chemistry ; and in Session 26, on chemical applications, the first paper, by Dr. R. Lindner, dealt with this subject. Another interesting paper in this Session, by members of the Kodak Research Laboratories, was on the determination of silver in photographic images using radioactive iodide (iodine131). Where a large number of analyses is required, the radio-iodination method has a distinct advantage over the potentiometric method and is to be preferred where only a small image is available, as in X-ray crystallographic patterns, or when the optical density is low.

The remaining four Sessions (27-30) were devoted respectively to ion exchange, non-destructive testing, static elimination and radioactivation analysis. Mr. K. Fearnside, of Isotope Developments, Ltd., Aldermaston, described four instruments : the transmission beta-ray thickness gauge used in paper, plastic sheet and metal foil production; the reflexion beta-ray gauge for the measurement of the thickness of coatings and liquid films; the gamma-ray thickness gauge applied to thick or hot-rolled metal strip ; and the package monitor used to check the contents of sealed packages as they leave the packaging machine. Mr. G. Syke dealt in more general terms with the problem of inspection and gauging with ionizing radiations. Fog-making on certain kinds of fabrics due to static electricity forming on the fibres can be prevented by dissipating the static when it occurs before it has time to become a nuisance. The static may be made to leak away either through the textile itself or through the surrounding air. Ionizing the air by means of a radioactive substance is a most successful method; and in his paper on radioactive static eliminators for the textile industry, Dr. P. S. H. Henry, of the Shirley Institute, discussed thoroughly the question of static on textiles and the relative merits of alpha- and beta-ray static eliminators. Finally, Mr. A. A. Smales gave some indications of the scope of radioactivation analysis, the essential basis of which is that an element is detected and determined by the formation of a radioactive nuclide which is then subjected to radioassay, and Prof. G. Chaudron described some work on the analysis of traces of sodium and copper in high-purity aluminium by pile activation.

\section{BREEDING-BACK OF THE TARPAN}

$\mathrm{B}$ FORE the existence of human culture a number of different kinds of wild horses existed in Europe and Asia. Of these only one is extant to-day. This one was discovered by the Russian Przewalski in the desert-like steppes of Zungaria in western Siberia. Like most steppe-dwelling animals, the Przewalski wild horse is red-brown in colouring and light underneath. As a legacy from its forbears it still carries zebra-like stripes at the backs of the legs which show up very clearly in the summer coat. The discovery of the last remaining species of wild horse was followed by the news that in the 1920's it had become extinct in the free state. To-day only a few are left scattered in various zoological gardens, and none is breeding except in the sixteen-head Munich herd.
It is on this herd that the hopes of preserving the species must rest.

If the species is not preserved, apart from its own interest, one of the most interesting animals of to-day will have become extinct. One of the European wild horses, the mouse-grey, for which the Russian name of tarpan has been adopted, was, in historical times, still extant over large areas of Europe (Oryx (Journal of the Fauna Preservation Society), 1, No. 7 ; November 1952).

In the first half of the past century it was still numerous in the steppes of the Ukraine north of the Black Sea. In 1876 it became extinct, leaving few traces of its existence. The tarpan was different from the Przewalski wild horse not only in colouring but also in build. The Przewalski has strong thick bones and an almost disproportionately heavy skull with narrow forehead which, many investigators believe, is the reason why the heavy carthorses of to-day are descended from this type. The tarpan has much finer bones and a short light head and is probably the progenitor of swift riding horses.

Distinguished for his successful efforts in breeding back the wild aurochs, Heinz Heck, director of the Tierpark Hellabrunn, Munich, has also successfully bred-back the tarpan. Mares from Iceland and Gothland that were markedly like tarpans were crossed with a Przewalski stallion; the resultant crosses were mated with one another and, in 1933, from this stock emerged the first foal with a mousegrey tarpan colouring. Other foals followed, and through resultant crossings there is to-day a considerable stock of back-bred tarpons in the Tierpark, Hellabrunn.

\section{MICROSCOPY OF PLANT ASHES}

7 TE statement that a microscope magnifies four hundred times never quite conveys a true idea of the wealth of detail that can be seen at this magnification. Perhaps only when the incredibly small fragments of material on a cosh, the minute amounts of blood or hair and other such negligible 'small dust of the balance', appear as important items of evidence in criminal proceedings is it realized how valuable is this instrument in the examination of such unpromising material.

One would, however, be pardoned in assuming that even the microscopist would have to admit defeat when dealing with material that had been so thoroughly incinerated that only an ash remained. However, in 1920, the Austrian botanist Hans Molisch investigated the structures left after incinerating plant material and showed that the ash still retained definite structural features. Prof. Gosta Edman, now professor of botany and pharmacognosy in the Royal Pharmaceutical Institute, Stockholm, was then a pupil of Molisch and later set out to investigate these 'ash pictures' systematically and has since published numerous papers on the subject. Recently he was awarded the Hanbury Memorial Medal of the Pharmaceutical Society of Great Britain which, in conjunction with the Linnean and Chemical Societies, periodically makes the award for "high excellence in the prosecution or promotion of original research in the Natural History and Chemistry of Drugs". After receiving the medal, Prof. Edman gave an account of his work on ash pictures (Pharm. J., 170,189 ; 1953). 